\title{
Influence of Binder Adhesion Ability on the Performance of Silicon/Carbon Composite as Li-Ion Battery Anode

\author{
Krzysztof Kierzek
}

(Submitted January 21, 2016; in revised form March 14, 2016; published online April 28, 2016)

\begin{abstract}
A series of anodes for Li-ion battery was prepared by conventional homogenization of active material, percolator, and $\mathrm{Na}-\mathrm{CMC}$ or several kinds of $\mathrm{PVDF}$ as a binder. $\mathrm{Si} / \mathrm{C}$ composite was synthesized by embedding micro-sized silicon and synthetic battery-grade graphite in a pitch-derived carbon matrix and taken as active material. Adhesion strength of anodic film to a current collector was determined by peeling test. Thermal relaxation $\left(120-180{ }^{\circ} \mathrm{C}\right)$ after calendering of PVDF-based anode slightly increases the adhesion of the film to the collector. The highest peeling strength was recorded for ultrahigh molecular weight PVDF $\left(\sim 0.05 \mathrm{~N} \mathrm{~cm}^{-1}\right)$ but without advantage for cycling stability of the cell. An initial reversible capacity of $512 \mathrm{mAh}^{-1}$, with average capacity decay only of $0.5 \%$ per cycle, was achieved for CMC-based anode of moderate peeling strength $\left(\sim 0.035 \mathrm{~N} \mathrm{~cm}^{-1}\right)$. Such good performance was attributed to a specific $\mathrm{Si} / \mathrm{C}$ composite structure as well as profitable physicochemical properties of the binder.
\end{abstract}

Keywords adhesives, calendering, CMC binder, energy, lithium, silicon/carbon composite

\section{Introduction}

Nowadays, the Li-ion batteries seem to be the best energy storage system for mobile applications. The system is still developed and, due to improving the cell construction and electrode materials performance, the capacity of the typical cell grows, approximately, by $10 \%$ annually (Ref 1 ). A positive electrode (cathode), generally built with lithium transition metal oxides, is more advance-prone due to not limited chemistry. However, an increase of specific capacity of cathode must be balanced by negative electrode (anode), which is mainly of synthetic graphite or graphite-like carbon (e.g., mesocarbon microbeads). Graphite has a theoretical specific capacity of $372 \mathrm{mAh} \mathrm{g}^{-1}$ and commercially available anodic materials are very close to this limit. Some disordered carbons demonstrate a higher capacity than graphite (about $500 \mathrm{mAh} \mathrm{g}^{-1}$ ), but with several serious drawbacks, like enhanced first cycle irreversible capacity and wide potential hysteresis between charge and discharge (Ref 2). Several metals can be electrochemically alloyed with $\mathrm{Li}$ at the potential similar to graphite and can play the role of anode in the Li-ion cell. The most promising is silicon of theoretical capacity around $4200 \mathrm{mAh} \mathrm{g}^{-1}$ (Ref 3). However, the application of the pure metal as anodic material is problematic because of a huge swelling (up to $300 \%$ ) leading to poor reversibility of lithium storage and quick mechanical disintegration. The drawbacks of silicon can be successfully reduced by dispersing metal nano- or micro-particles in the conductive matrix (favorably ordered carbon) to accommodate

Krzysztof Kierzek, Department of Polymer and Carbonaceous Materials, Faculty of Chemistry, Wroclaw University of Technology, Gdanska 7/9, 50-344 Wroclaw, Poland. Contact e-mail: krzysztof. kierzek@pwr.edu.pl. the silicon expansion and to assure the electrode conductivity on a reasonable level to facilitate the charge transfer to the hosts (Ref 4-7).

Earlier studies show that the performance of conventional graphitic anode is strongly dependent on the adhesion strength of electrode film to a current collector (Ref 8,9). Attempts to increase adhesive attractions include applying specific binder (Ref 10,11) and modifying the surface of current collector (Ref 12) or active material (Ref 13). In contrast, for Si-based anode the relation of cycle-life with adhesion is suggested based on the general knowledge about binder (Ref 14, 15) or current collector physicochemistry (Ref 16) but without direct proofs, like a peeling test measurement. Simple comparison of data from different reports is insufficient to clarify the matter because of various electrode preparation techniques and electrochemical conditions applied. In some cases the superior durability of Si-based anode can be attributed rather to the extreme electrode porosity due to excess amount of the binder and percolator as well as lack of mechanical post-treatment (Ref 17).

Within this context, the objective of this work is to validate the adhesive strength of Si-based anodic film to the copper current collector, as a factor influencing cycle-life of the cell. Several polymeric binders of wide spread of physical and chemical properties were selected for the evaluation. All electrodes were prepared with standardized procedures, referring to industrial Li-ion manufacturing. The results of peeling tests were faced with average capacity decays assessed from electrochemical experiments.

\section{Experimental Section}

\subsection{Thermal Properties of Binders}

The differential scanning calorimetry (DSC), Mettler DSC821e, was used to evaluate the thermal behavior of pure binders. The materials were heated in air up to $300{ }^{\circ} \mathrm{C}$ with the rate of $5{ }^{\circ} \mathrm{C} \mathrm{min}^{-1}$. The main purpose of DSC measurement was recognizing a melting temperature of binders. It allowed to 
fix an upper temperature limit for further thermal relaxation of anodes.

\subsection{Si/C Composite Powder Preparation}

Only cheap and easily available raw materials were used for $\mathrm{Si} / \mathrm{C}$ composite preparation: silicon micro-powder (Aldrich, below 325 mesh), synthetic battery-grade graphite powder (TIMREX ${ }^{\circledR}$ SLP30, TIMCAL), and particulate matter-free coal-tar pitch ( $\mathrm{SP}=97^{\circ} \mathrm{C}$, Mettler). Silicon and graphite were main electrochemically active components. Additional role of graphite was to increase the intrinsic conductivity of the final $\mathrm{Si} / \mathrm{C}$ particles. Silicon and graphite powders were embedded in a soft-carbon matrix produced from coal-tar pitch. The pitchcoke has contributed partly to the overall capacity.

The composite particles were fabricated in few steps, including in sequence ball-milling of component mixture in toluene suspension, heating at $520{ }^{\circ} \mathrm{C}$ to pyrolyse pitch, grounding to a particle size below $63 \mu \mathrm{m}$, and final heattreatment at $1100{ }^{\circ} \mathrm{C}$ for $3 \mathrm{~h}$. The detailed procedure was described in an earlier work (Ref 18). The composite with silicon contribution of 12 wt. $\%, 70$ wt. $\%$ of graphite, and 18 wt.\% of pitch-coke was prepared.

\subsection{Electrode Preparation}

A series of electrodes was prepared with 85 wt.\% of $\mathrm{Si} / \mathrm{C}$ composite, 5 wt. $\%$ of carbon black as conductive additive (C-NERGY ${ }^{\mathrm{TM}}$ SUPER C65, TIMCAL), and $10 \mathrm{wt} \%$ of binder. The binders used in the work included three poly(vinylidene) difluoride (PVDF) resins (Arkema, France): functionalized homopolymer Kynar ADX (ADX), high molecular weight homopolymer Kynar HSV900 (HSV), and the mixture of ADX/ HSV in the $1: 1$ ratio, as well as cellulose derivative, sodium salt of carboxymethylcellulose from Aldrich (CMC). The electrodes were prepared using the following protocol. First, a slurry was obtained by mixing the $\mathrm{Si} / \mathrm{C}$ composite and carbon black with N-methylpyrrolidone, NMP (PVDF resins), or water (CMC) solution of binder. In case of water-based suspension, 3 wt. $\%$ of styrene-butadiene-rubber, SBR (MTI Corp., USA) as plasticizer and small amount of non-ionic surfactant (Tween 20, Aldrich) were admixed. The slurry was cast on battery-grade copper foil (Schlenk, Germany, $25 \mu \mathrm{m}$ ) used as a current collector. The solvent was evaporated at $120{ }^{\circ} \mathrm{C}$ on a horizontal hot plate and, finally, dried under vacuum overnight. The dry film was pressrolled to $60 \%$ of the initial film thickness and the final electrodes were 60-70 $\mu \mathrm{m}$ thick, excluding the current collector. After calendering, selected PVDF-based anodes were annealed at 140,160 , and $180{ }^{\circ} \mathrm{C}$ for $1 \mathrm{~h}$ for polymer relaxation. The resultant electrodes were marked as "BBBTTT," where "BBB" and "TTT" represent an abbreviation of binder type and temperature treatment, respectively (e.g., CMC-120).

\subsection{Peel Test}

A peeling strength was measured to assess the adhesion between the electrode film and the current collector. A 180 degree test was performed, based on ASTM D3330 standard, where the electrode tape of $25 \mathrm{~mm}$ width was applied to a vertical metal plate which was pulling up, away from the secured end of the tape, with a speed of $20 \mathrm{~mm} \mathrm{~s}^{-1}$. Three samples of each electrode kind were measured. The average value with standard deviation was shown in the results.

\subsection{Electrochemical Measurements}

Working electrodes with a diameter of $15 \mathrm{~mm}$ were punched-out from the parent one, dried under vacuum at $120^{\circ} \mathrm{C}$ overnight to remove traces of water and, finally, introduced in an argon-filled glove-box. Electrochemical testing was performed in coin-type cells (CR2032, Hohsen Corp., Japan), which were assembled with the $\mathrm{Si} / \mathrm{C}$-based electrode as anode and a metallic lithium foil as cathode and reference electrode. The electrolyte used was a $1 \mathrm{M}$ solution of lithium hexafluorophosphate $\left(\mathrm{LiPF}_{6}\right)$ in a $1: 1(\mathrm{v} / \mathrm{v})$ mixture of EC (ethylene carbonate) and DMC (dimethyl carbonate). A glass microfiber separator (Whatman, GF/F, thickness of $420 \mu \mathrm{m}$ ), wetted with the electrolyte, was sandwiched between the carbon electrode and the Li metal foil.

The cells were investigated by galvanostatic cycling using a VMP3 (Biologic, France) multichannel generator. The charging/discharging rate was set at $C / 5$, where " $C$ " corresponds to the theoretical capacity of graphite $\left(372 \mathrm{mAh} \mathrm{g}^{-1}\right)$ discharged in $1 \mathrm{~h}$. Cut-off potentials were fixed to 0.005 and $1.5 \mathrm{~V}$ versus $\mathrm{Li} / \mathrm{Li}^{+}$. The galvanostatic characteristics of the cells were used to determine the reversible capacity $\left(C_{\text {rev }}\right)$, irreversible capacity $\left(C_{\text {irr }}\right)$, and the coulombic efficiency (CE) defined as the ratio of deinsertion to insertion charge expressed in percent. All capacities were related to the mass of $\mathrm{Si} / \mathrm{C}$ composite in the anode.

\subsection{Electrode Morphology Analysis}

The morphologies of anode surfaces before and after electrochemical test were observed by scanning electron microscopy (JEOL JSM-6610LVnx). After 30 cycles of lithium insertion/deinsertion, the test cells were disassembled. The anodes were washed thoroughly with DMC to remove the electrolyte and finally dried at room temperature.

\section{Results and Discussion}

\subsection{Differential Scanning Calorimetry}

DSC curves of the pure binders are presented in Fig. 1. The both PVDF-based resins melt in the range of 150 and $170{ }^{\circ} \mathrm{C}$. Stronger endothermal effect during ADX melting is related to higher polarity of this binder. The PVDF-based resins are thermochemically stable up to $300{ }^{\circ} \mathrm{C}$. CMC does not melt. Evolution of adsorbed water and/or endothermic decomposition

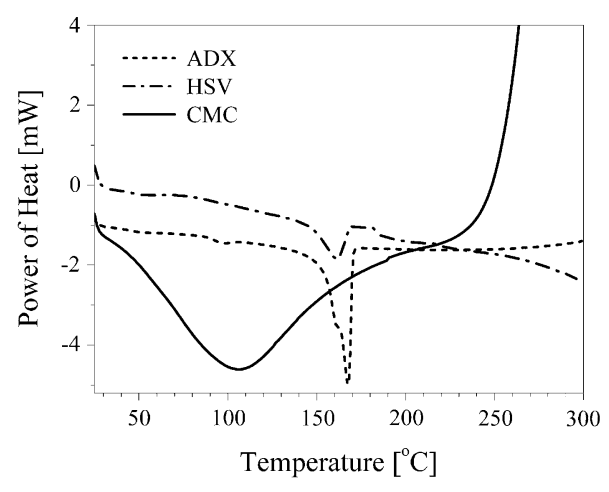

Fig. 1 DSC curves of the pure binders 
of functional groups is observed up to $150{ }^{\circ} \mathrm{C}$. The oxidation of the binder occurs in air above $230{ }^{\circ} \mathrm{C}$. According to the DSC data, the PVDF-based anodes were annealed only up to $180{ }^{\circ} \mathrm{C}$. The CMC-based anode was not treated at elevated temperature.

\subsection{Peeling Strength}

Figure 2 shows the normalized peeling strength of all electrodes prepared. In the group of materials treated at $120{ }^{\circ} \mathrm{C}$, the electrode with HSV shows the highest peeling strength. It can be ascribed to the high molecular weight of this resin $\left(\mathrm{MW} \sim 1\right.$ million $\mathrm{g} \mathrm{mol}^{-1}$ ). The $\mathrm{CMC}$ binder $\left(\mathrm{MW}=700,000 \mathrm{~g} \mathrm{~mol}^{-1}\right.$ ) allows to prepare the electrode of moderate mechanical properties. Assuming the high amount of functional groups in $\mathrm{ADX}$, this resin should provide a strong adhesion of the film to the copper foil. However, in the test conditions, the lowest peeling strength was recorded for ADX120 electrode. The blend of PVDF-based resins does not give the electrode of average adhesion properties, as it could be expected. ADX/HSV-120 shows mechanical behavior rather similar to ADX-120.

Annealing electrodes, produced from ADX/HSV blend at elevated temperature, slightly increases the adhesion of the film to the current collector, probably, as an effect of relaxation of mechanical stress created during electrode calendering. However, the treatment above melting point of polymers does not induce significant benefit. The peeling strength of ADX/HSV180 electrode is higher only by $16 \%$ than that of the parent ADX/HSV-120.

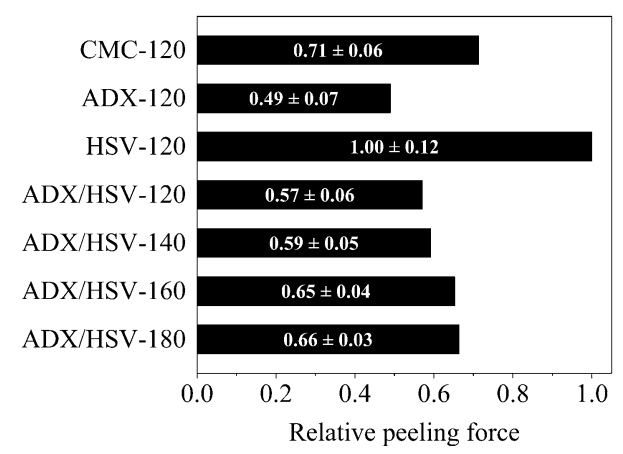

Fig. 2 Normalized peeling strength of the electrodes. A value 1 corresponds to peeling force of $0.049 \pm 0.006 \mathrm{~N} \mathrm{~cm}^{-1}$. The numerical data with standard deviation are shown on the bars

\subsection{Electrochemical Measurements}

The galvanostatic curves of the first discharge/charge cycle of electrodes obtained by using different binders are shown in Fig. 3(a). Very similar charge/discharge characteristics and large initial reversible capacity of about $600 \mathrm{mAh} \mathrm{g}^{-1}$, were measured for all the PVDF-based electrodes. The irreversible capacity is only $100 \mathrm{mAh} \mathrm{g}^{-1}$, which can be attributed mainly to the good performance $\mathrm{Si} / \mathrm{C}$ composite used as the active material (Ref 18). Accordingly, the initial coulombic efficiency is relatively high $(\mathrm{CE} \sim 86 \%)$. Applying CMC deactivates a part of the composite. The first cycle $C_{\text {rev }}$ and $C_{\text {irr }}$ decrease down to 512 and $53 \mathrm{mAh} / \mathrm{g}$, respectively; however, the irreversible lithium trapping is depleted to a larger extent, which results in higher coulombic efficiency of $90 \%$ than in other anodes.

The binder impact is more pronounced in prolonged test (Fig. 3b). Anode with CMC binder represents excellent cycling properties. The capacity decay is only $14 \%$ after 30 cycles and the coulombic efficiency is above $99 \%$. Under the same conditions, the anode with HSV resin loses about $60 \%$ of the initial capacity and $\mathrm{CE}$ is in the range of $96-98 \%$. Admixing ADX to the HSV slightly improves cycling properties of the cell. The anode with pure ADX binder shows the worst behavior with $73 \%$ of capacity decay. For the last electrode, significant capacity drop occurs between the fifth and the fifteenth cycle, which is reflected in the higher CE fluctuation.

Annealing HSV/ADX electrodes at temperature above $120^{\circ} \mathrm{C}$ does not change the initial $C_{\text {rev }}$ and $C_{\text {irr }}$ as well as the shape of galvanostatic curves of the first discharge/charge cycle. Some differences appear only during cycling (Fig. 4). Unexpectedly, all electrodes treated at elevated temperature show worsening cycleability after the tenth cycle compared to the parent material. Such behavior is contrary to the peeling strength increase (Fig. 2).

The results show that there is no clear correlation between adhesive properties of the binder used and cycle-life of the anode (Fig. 5). All PVDF polymers do not provide high durability of Si/C-based anode. The anodic mass with HSV, of the highest adhesive strength to current collector, shows the significant capacity decay, at the level of $12 \mathrm{mAh} \mathrm{g}^{-1}$ cycle $^{-1}$. The stiffness and attraction of the resin to the $\mathrm{Si} / \mathrm{C}$ particles (silicon and carbon phase) is insufficient to eliminate the change of anode microstructure during charging/discharging. On the other hand, the CMC-based electrode demonstrates
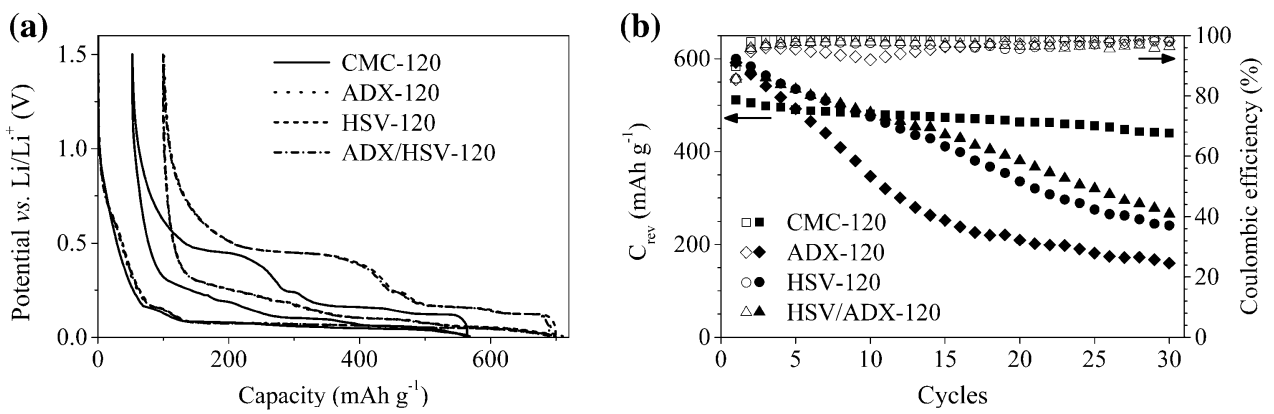

Fig. 3 Potential profiles of the first discharge/charge cycle (a) and cycleability (b) of anodes prepared with different binders and treated at $120^{\circ} \mathrm{C}$ 
relatively good cycle-life, recognized as capacity decay of only $2.4 \mathrm{mAh} \mathrm{g}^{-1}$ cycle $^{-1}$, in spite of moderate peeling strength $\left(0.035 \mathrm{~N} \mathrm{~cm}^{-1}\right)$.

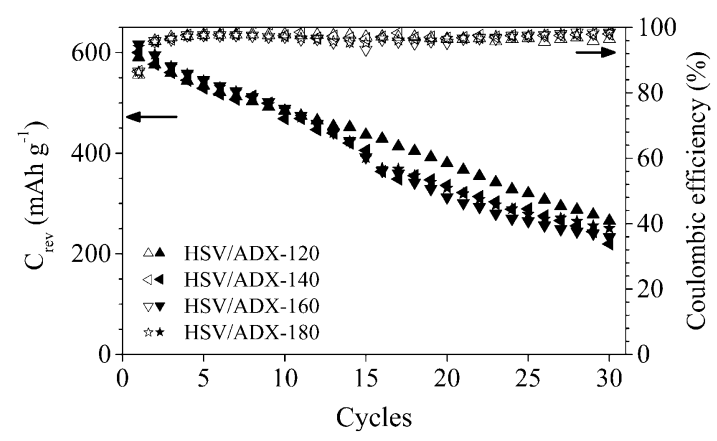

Fig. 4 Cycleability of anodes prepared with HSV/ADX binder and treated at elevated temperatures

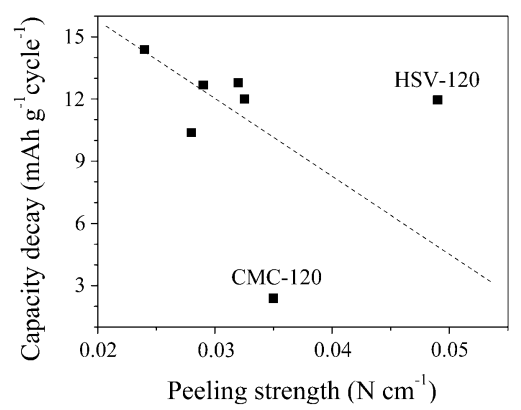

Fig. 5 Relationship between adhesion of the anodic films to the current collector and average capacity decay of the cell
The electrochemical behavior of anodes is in good agreement with SEM observation of their surface morphology before and after cycling (Fig. 6). Pairs of anodes selected for the study included CMC-120 of the highest electrochemical stability, HSV-120 of the highest peeling strength, and ADX-120 of the lowest peeling strength. It must be noted, that after 30 charge/ discharge cycles, both the PVDF-based anodic films are completely detached from the current collector, whereas the CMC-120 film is clung to the copper. Before cycling all the anodes show smooth and not defected surface. CMC-120 has a little less compacted structure with some macropores of size of 20-50 $\mu \mathrm{m}$. After electrochemical tests, the CMC-120 has still smooth surface (Fig. 6d). In contrast, the significant surface roughness and several cracks can be observed on ADX-120 and HSV-120 films (Fig. 6e, f). It is an evidence that the mechanical strength of both PVDF-based binders is insufficient to persist $\mathrm{Si} / \mathrm{C}$ particles swelling during lithium insertion.

The better mechanical durability and electrochemical performance of the $\mathrm{CMC}-120$ cell seem to result from a high stiffness of CMC network and chemical interaction with the silicon phase (Ref 17). In this case, the adhesion strength to the copper foil is a less significant parameter. It suggests that the presence of carboxylic groups in CMC chains is demanded. The recent reports (Ref 19, 20) show that the effect is related to the hydrogen and ester bonds between the polymer and oxidized surface of silicon. Moreover, better cycleability is observed when the CMC-based anode is exposed to humid air before cell assembling (Ref 19), which is contrary to the standard industry practice. Based on this point, a further improvement in the cell performance seems to be possible by optimizing the anode preparation technique as well as CMC properties (molecular weight and degree of carboxymethyl substitution (Ref 21)) or its content in the anode.
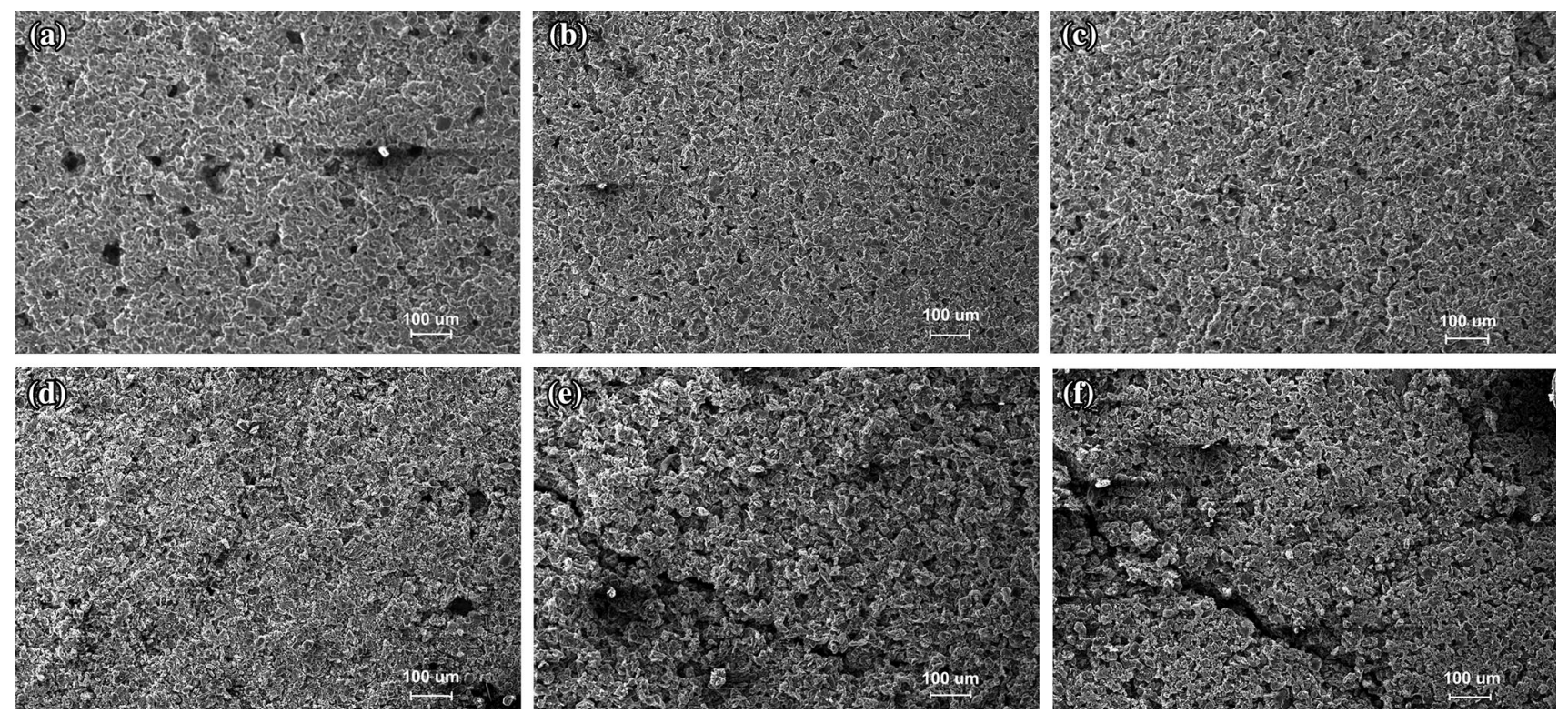

Fig. 6 SEM images of CMC-120, ADX-120, HSV-120 anodes before (a, b, c, respectively) and after (d, e, f, respectively) 30 cycles of charge/ discharge 


\section{Conclusions}

The silicon/carbon composite, produced from cheap and common parent materials using facile synthesis procedure, shows good cycling stability as anodic material of Li-ion cell when mixed with appropriate binder. Among various binders tested in this work, only CMC could ensure good electrochemical performance of $\mathrm{Si} / \mathrm{C}$ composite, thanks to the specific physicochemical properties. Unlike in the case of conventional graphite-based anode, the adhesive strength of the electrode film to the current collector is not a key parameter for a good cycle-life of the cell.

\section{Acknowledgments}

The research was supported by the Wrocław Research Centre EIT + within the project "The Application of Nanotechnology in Advanced Materials"-NanoMat (POIG.01.01.02-02-002/08) cofinanced by the resources of European Fund of Regional Development (PO IG 1.1.2) and by a statutory activity subsidy from the Polish Ministry of Science and Higher Education for the Faculty of Chemistry of Wrocław University of Technology.

\section{Open Access}

This article is distributed under the terms of the Creative Commons Attribution 4.0 International License (http://creativecommons. org/licenses/by/4.0/), which permits unrestricted use, distribution, and reproduction in any medium, provided you give appropriate credit to the original author(s) and the source, provide a link to the Creative Commons license, and indicate if changes were made.

\section{References}

1. H. Takeshita, The 24th International Battery Seminar and Exhibit (Fort Lauderdale), Florida Educational Seminars, 19-22 March 2007

2. T. Zheng and J.R. Dahn, Application of carbon in lithium-ion batteries, Carbon Materials for Advanced Technologies, T.D. Burchell, Ed., Pergamon, Amsterdam, 1999, p 341-387

3. G.X. Wang, J.H. Ahn, J. Yao, S. Bewlay, and H.K. Liu, Nanostructured Si-C Composite Anodes for Lithium-Ion Batteries, Electrochem. Commun., 2004, 6, p 689-692

4. Y. Liu, K. Hanai, J. Yang, N. Imanishi, A. Hirano, and Y. Takeda, Silicon/Carbon Composites as Anode Materials for Li-Ion Batteries, Electrochem. Solid-State Lett., 2004, 7, p A369-A372

5. W.R. Liu, J.H. Wang, H.C. Wu, D.T. Shieh, M.H. Yang, and N.L. Wu, Electrochemical characterizations on $\mathrm{Si}$ and $\mathrm{C}$-coated $\mathrm{Si}$ particle electrodes for lithium-ion batteries, J. Electrochem. Soc., 2005, 152, p A1719-A1725

6. N. Dimov, S. Kugino, and M. Yoshio, Mixed Silicon-Graphite Composites as Anode Material for Lithium Ion Batteries: Influence of Preparation Conditions on the Properties of the Material, J. Power Sources, 2004, 136, p 108-114

7. M. Majima, S. Ujiie, E. Yagasaki, S. Inazawa, and K. Miyazaki, Examination on Battery Technology for Scale-up of a Lithium Ion Battery, Electrochemistry, 2000, 68, p 167-173

8. Y. Eker, K. Kierzek, E. Raymundo-Pinero, J. Machnikowski, and F. Beguin, Effect of Electrochemical Conditions on the Performance Worsening of $\mathrm{Si} / \mathrm{C}$ Composite Anodes for Lithium Batteries, Electrochim. Acta, 2010, 55, p 729-736

9. M. Despotopoulou and M.T. Burchill, Coatings for Electrochemical Applications, Prog, Org. Coat., 2002, 45, p 119-126

10. M. Yoo, C.W. Frank, S. Mori, and S. Yamaguchi, Effect of Poly(vinylidene fluoride) Binder Crystallinity and Graphite Structure on the Mechanical Strength of the Composite Anode in a Lithium Ion Battery, Polymer, 2003, 44, p 4197-4204

11. J.-H. Lee, U. Paik, V.A. Hackley, and Y.-M. Choi, Effect of Poly(acrylic acid) on Adhesion Strength and Electrochemical Performance of Natural Graphite Negative Electrode for Lithium-Ion Batteries, J. Power Sources, 2006, 161, p 612-616

12. S. Lee and E.-S. Oh, Performance Enhancement of a Lithium Ion Battery by Incorporation of a Graphene/Polyvinylidene Fluoride Conductive Adhesive Layer Between the Current Collector and the Active Material Layer, J. Power Sources, 2013, 244, p 721-725

13. Y. Cao, L. Xiao, X. Ai, and H. Yang, Surface-Modified Graphite as an Improved Intercalating Anode for Lithium-Ion Batteries, Electrochem. Solid-State Lett., 2003, 6, p A30-A33

14. U. Farooq et al., Effect of Binder and Composition Ratio on Electrochemical Performance of Silicon/Graphite Composite Battery Electrode, Materials Lett., 2014, 136, p 254-257

15. M.T. Jeena, J.-I. Lee, S.H. Kim, C. Kim, J.-Y. Kim, S. Park, and J.-H. Ryu, Multifunctional Molecular Design as an Efficient Polymeric Binder for Silicon Anodes in Lithium-Ion Batteries, ACS Appl. Mater. Interfaces, 2014, 6, p 18001-18007

16. N.-R. Shin, Y.-M. Kang, M.-S. Song, D.-Y. Kim, and H.-S. Kwon, Effects of Cu Substrate Morphology and Phase Control on Electrochemical Performance of Sn-Ni Alloys for Li-Ion Battery, J. Power Sources, 2009, 186, p 201-205

17. J.S. Bridel, T. Azaïs, M. Morcrette, J.M. Tarascon, and D. Larcher, Key Parameters Governing the Reversibility of $\mathrm{Si} / \mathrm{Carbon} / \mathrm{CMC}$ Electrodes for Li-Ion Batteries, Chem. Mater, 2010, 22, p 1229-1241

18. K. Kierzek, J. Machnikowski, and F. Béguin, Towards the Realistic Silicon/Carbon Composite for Li-Ion Secondary Battery Anode, $J$. Appl. Electrochem., 2015, 45, p 1-10

19. C. Reale Hernandez, Z. Karkar, D. Guyomard, B. Lestriez, and L. Roué, A Film Maturation Process for Improving the Cycle Life of SiBased Anodes for Li-Ion Batteries, Electrochem. Commun., 2015, 61, p 102-105

20. L. Wei, C. Chen, Z. Hou, and H. Wei, Poly (acrylic acid sodium) Grafted Carboxymethyl Cellulose as a High Performance Polymer Binder for Silicon Anode in Lithium Ion Batteries, Sci. Rep., 2016, 6, p 19583. doi:10.1038/srep19583

21. J.-H. Lee, U. Paik, V.A. Hackley, and Y.-M. Choi, Effect of Carboxymethyl Cellulose on Aqueous Processing of Natural Graphite Negative Electrodes and Their Electrochemical Performance for Lithium Batteries, J. Electrochem. Soc., 2005, 152, p A1763-A1769 